\title{
МНОГОЛЕТНЯЯ ДИНАМИКА И ПРОГНОЗ СТОКА ТЯЖЕЛЫХ МЕТАЛЛОВ НА НИЖНЕЙ ВОЛГЕ В СВЯЗИ С РЕАЛИЗАЦИЕЙ ГОСУДАРСТВЕННОЙ ПРОГРАММЫ «ОЗДОРОВЛЕНИЕ ВОЛГИ»
}

\author{
В. О. Татарников, Е. В. Гаврилова \\ Каспийский морской научно-исследовательский центр, Россия \\ Поступила в редакиию 5 августа 2018 г.
}

\begin{abstract}
Аннотация: Для современного периода характерно снижение концентрации меди и цинка в воде реки Волга. В статье объясняется, что наблюдаемое снижение связано как с изменением естественных условий, так и с общим уменьшением уровня антропогенного воздействия. Предстоящая реализация государственной программы «Оздоровление Волги» способна снизить содержание металлов до уровня естественного фона. Наибольших результатов от реализации программы можно будет ожидать при снижении стоков от промышленных предприятий.
\end{abstract}

Ключевые слова: Волга, тяжелые металлы, программа «Оздоровление Волги», промышленные стоки, стоки ЖКХ, фоновая концентрация.

Abstract: The current period is characterized by reduced concentrations of copper and zinc in the Volga water. The article explains that the observed reduction is due to both changes of the natural conditions and to the overall decrease of anthropogenic impact. The expected implementation of the stateinitiated programme «The Volga Rehabilitation» can help reduce the content of metals to background levels. The best possible results of the programme implementation can be expected in case the industrial discharges are reduced.

Key words: Volga River, heavy metals, programme «The Volga Rehabilitation», industrial discharge, municipal wastewater, background concentration.

Экологическое состояние Волги в современное время оценивается как критическое. Неудовлетворительное состояние реки призвана улучшить государственная программа «Оздоровление Волги». Одной из целью данной программы заявлено снижение в ближайшие годы количества поступающих загрязненных вод в девять раз (http:// government.ru/news/28770/). Хотелось бы полагать, что такое снижение количества поступающих загрязненных вод повлечет пропорциональное снижение концентрации загрязняющих веществ. Очевидно, зафиксировав нынешнее состояние загрязненности вод, мы сможем оценить последствия реализации данной программы.

Одним из весомых компонентов загрязнения речных вод являются тяжелые металлы. В естественных условиях они в малых количествах попадают путем миграции из почвы и с атмосферным переносом. Однако основным источником загрязненности металлами на данный момент вы-

() Татарников В.О., Гаврилова Е.В., 2019 ступает хозяйственная деятельность человека. Так, в регионе сосредоточено около половины промышленного потенциала России и свыше трети сельскохозяйственных угодий. Основные тяжелые металлы, сбрасываемые в водотоки Волги, это медь и цинк [12]. Их присутствие в природной среде необходимо для нормального развития биологических сообществ, но техногенное повышение их содержания может угнетать развитие организмов. Более того, накапливаясь в пищевой цепочке, или напрямую попадая с питьевой водой, металлы поступают в человеческий организм. Длительное воздействие тяжелых металлов может вызывать отклонения в здоровье человека [5].

\section{МАТЕРИАЛЫ И МЕТОДЫ}

Материалом исследования послужили многолетние наблюдения Астраханского центра гидрометслужбы у с. Верхнелебяжье. Пункт наблюдений расположен в 55 км вверх по течению от Астрахани. Мониторинг организован в 1978 году и продолжается в настоящее время. В 90-е годы об- 


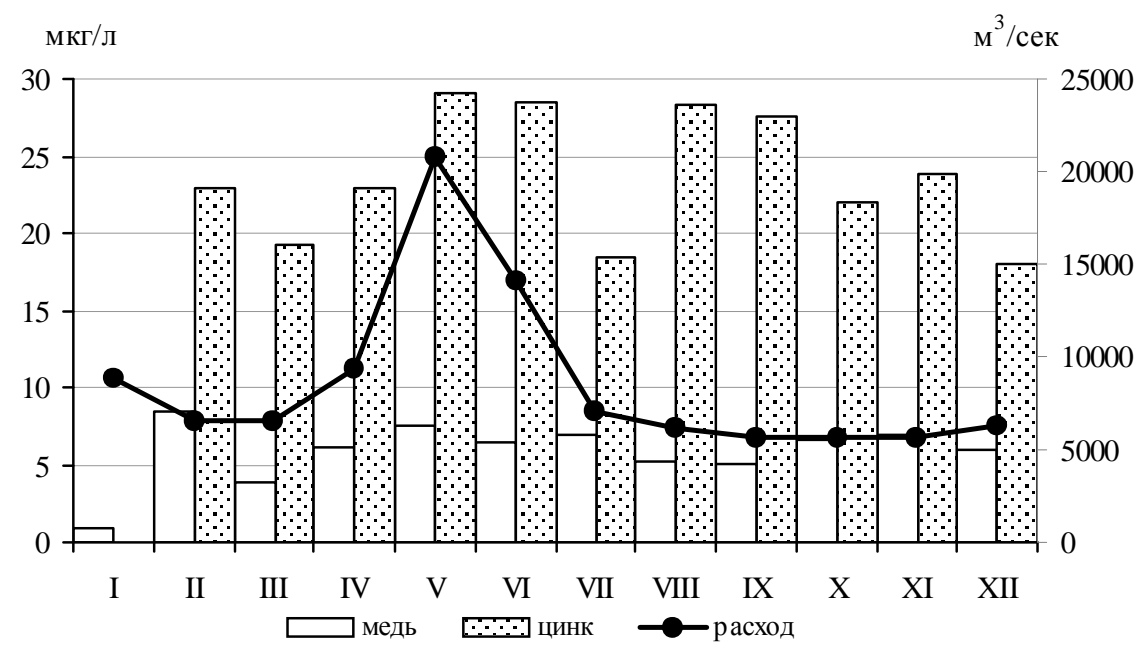

Puc. 1. Сезонная динамика меди и цинка у села Верхнелебяжье по данным 1978-2016 годов

щее количество наблюдений снизилось, но в последнее время приблизилось к значениям советского периода, а в некоторые месяцы и превосходит.

Наблюдения у села Верхнелебяжье, расположенного в вершине дельты Волги, могут характеризовать состояние общей загрязненности большей части дельты и отражать степень антропогенной нагрузки большей части Европейской территории России.

Для анализа рядов данных мы использовали стандартный набор статистических методик, включающих скользящее среднее, корреляционный анализ.

\section{РЕЗУЛЬТАТЫ И ОБСУЖДЕНИЕ}

Основным фактором, определяющим динамику меди и цинка в воде Волги является речной сток $[21,18]$. Как правило, повышенные концентрации меди и цинка регистрируются в период половодья, воды которого по большей части формируются на поверхности водосбора. В тоже время существуют различия в сезонной динамике металлов. Наибольшие значения концентрации меди регистрировались в феврале, мае и ноябре (рис. 1), цинкав мае-июне и августе-сентябре. Следует отметить, что гидрограф, здесь и далее, построенный по расходам воды, наблюдавшимся во время отбора проб, имеет только один пик - в мае. Тогда можно предположить, что осенние пики концентрации, скорее всего, связаны с антропогенным влиянием. Обращается внимание на то, что если «естественный» ход концентрации металлов определялся бы исключительно стоком, то на протяжении августа-декабря их накопление должно было находиться на одном уровне. Для цинка эта величина, примерно, составила бы 15 мкг/л, для меди - 5 мкг/л.
Превышение над нормами в среднем составило для меди 1 мкг/л, для цинка 9 мкг/л. Предполагаемая антропогенная составляющая добавляет к концентрации 20-60\%.

Данные расчеты, по-видимому, показывают добавочное влияние промышленных центров, расположенных между селом Верхнелебяжье и городом Волгоград. Основное превышение вносят промышленные стоки города Волгограда, которые поступают непосредственно в русло Волги ниже Волжской плотины. Резкую разницу между концентрацией металлов в воде Волжского водохранилища и в воде дельты Волги отмечали еще в прошлом веке [4]. При этом превышение над концентрацией цинка, наблюдаемой в Волжском водохранилище, относительно концентрации в водотоках дельты составляла порядка $80 \%$, что достаточно хорошо соотносится с нашими расчетами (превышение $60 \%$ ). Тоже самое нельзя утверждать для концентрации меди. Здесь в конце 80-х годов превышение над значениями, наблюдаемыми в водохранилище, составляли около $100 \%$ (в отличие от $20 \%$ ), что, скорее всего, вызвано сменой характера процессов способствующих поступлению меди в реку.

Февральская концентрация меди оказалась наибольшей, а концентрация цинка, наблюдаемая в феврале, не сильно отличалась от уровня концентрации, наблюдаемой в период половодья. Отметим, что зимние месяцы характеризуются низкими значениями концентрации взвешенного вещества [11] и на вновь поступающие растворенные формы металлов с промышленными и хозбытовыми стоками приходится гораздо меньше свободных ячеек адсорбции. Это может быть одной 
Многолетняя динамика и прогноз стока тяжельх металлов на Нижней Волге в связи с реализащией государственной программы «Оздоровление Волги»

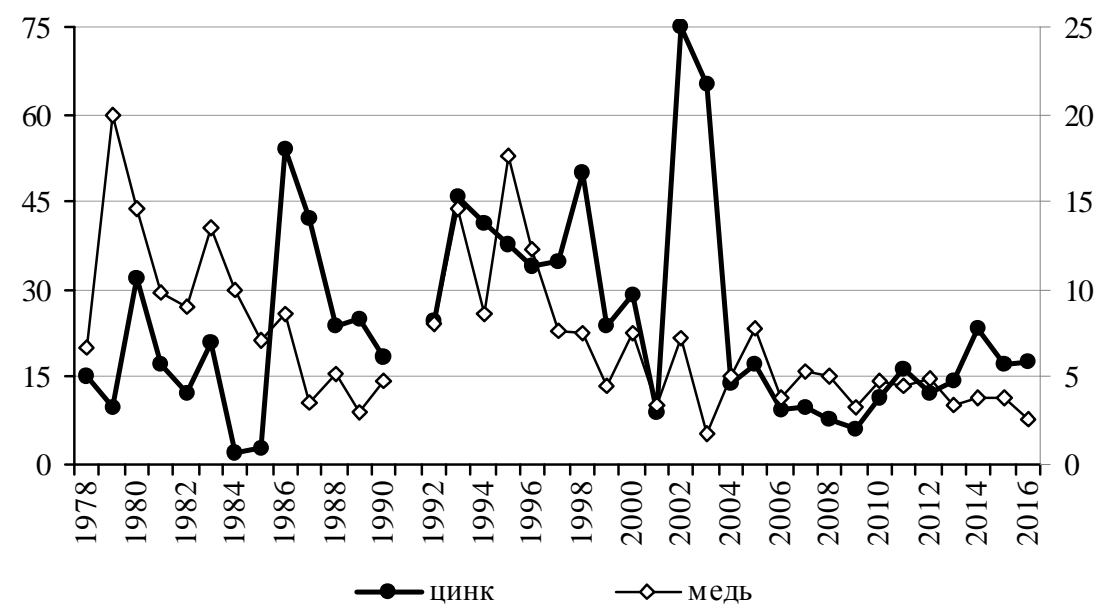

Puc. 2. Многолетняя динамика цинка (шкала слева, мкг/л) и меди (шкала справа, мкг/л) у села Верхнелебяжье

из причин высокого уровня концентрации тяжелых металлов, регистрируемых в феврале.

Анализируя многолетнюю динамику меди и цинка (рис. 2), можно выделить несколько периодов с характерным поведением концентрации. Первый период полностью совпадает со временем существования СССР - до 1991 года. Для него характерны высокие, порой максимальные, значения концентрации, но отмечалось постепенное их снижение к концу периода, что особенно характерно для меди. Второй период, который условно можно назвать периодом деградации и последующего восстановления экономики, наблюдалось резкое увеличение концентрации тяжелых металлов до значений первого периода, и последующее их снижение к 2004 году. Третий период с 2004 года по нынешнее время характеризуется стабильно низкими значениями концентрации меди и цинка.

Стоит отметить, что в период с 1978 года сток Волги также претерпел кардинальные изменения. С 1978 года начинается многоводный период сток резко возрастает. Период длится до середины 90-х годов, после чего наблюдается стабилизация и некоторое снижение количественных показателей стока. Так, значение расхода в первый период составило $9585 \mathrm{~m}^{3} /$ сек, концентрация меди 8,16 мкг/л, цинка - 23,0 мкг/л. Во второй период 9490 м³/сек, медь - 7,60 мкг/л, цинк - 40,9 мкг/л, в третий период - $7753 \mathrm{~m}^{3} /$ сек, медь - 4,41, цинк 13,3. Приведенные данные показывают, что почти одинаковые значения расходов, наблюдаемые в первом и втором периодах, соотносятся с одинаковым уровнем концентрации меди, и повышенным уровнем цинка. Уменьшение расхода воды, наблюдаемое в третьем периоде, соотносится со снижением концентрации металлов. Иными сло- вами тренд многолетней динамики металлов, скорее всего, задавался особенностями гидрологического режима Волги. Данный вывод становится еще более очевиден, если прокоррелировать осредненные скользящим средним по 51 значению исходных данных по расходу Волги и концентрации металлов. В итоге полученные корреляции 0,50 для меди, 0,48 для цинка при $n=623$ значения и уровне $p=0,001$ будут значимыми.

В первом периоде можно выделить тренды, не связанные с уровнем расхода воды. Так, линейный тренд меди в первом периоде был отрицательным, цинка - положительным, а расход воды - практически отсутствовал. Если общей тенденцией концентрации меди было ее снижение, то у цинка, резкое снижение отмечается с 1986 года, что положительно влияли природоохранные мероприятия. К 1989 году степень очистки промышленных стоков до нормативного уровня достигала $34 \%$ [8]. Постоянно увеличивалась доля оборотной и последовательно используемой воды, вводились новые системы замкнутого водоснабжения и очистные сооружения. Уменьшению загрязненности реки будет способствовать введение в строй новых очистных сооружений, увеличение доли повторного использования воды, использование технологий замкнутого водоснабжения. Возрастанию загрязненности - возрастание объема сточных вод сбрасываемых в Волгу, водопотребление на производственные нужды.

Возвращаясь к трендам тяжелых металлов, наблюдаемым в первый период, можно предположить, что усилия направленные на снижение загрязненности воды в большей степени отразились на динамике меди, чем цинка, однако, и его концентрация в конце периода также снижалась. 

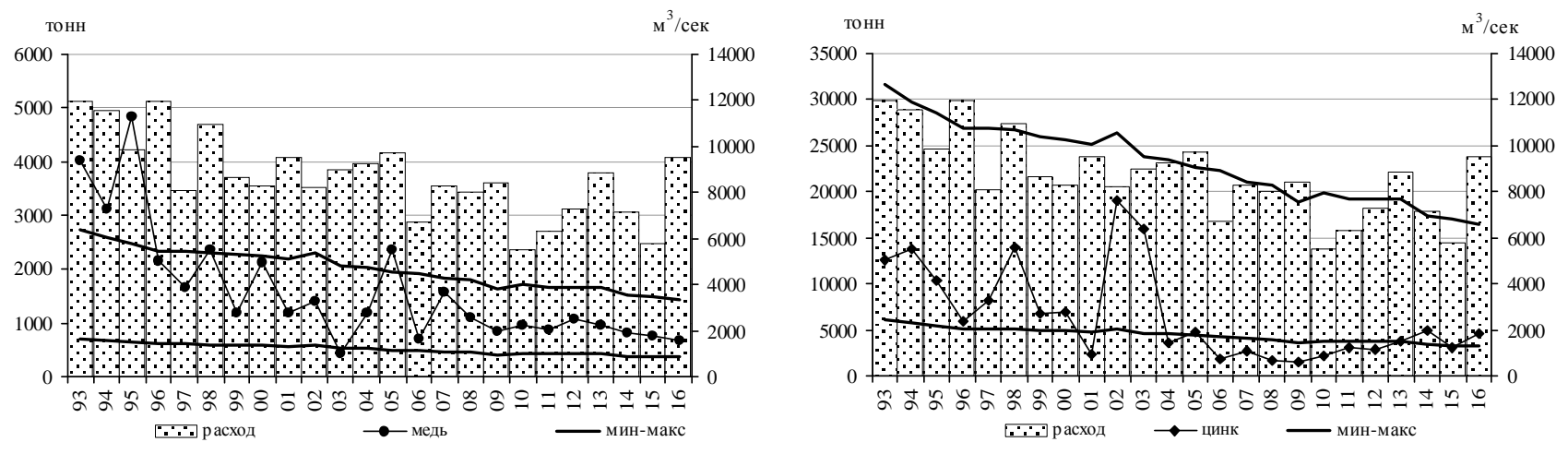

Puc. 3. Расчетный (сплошная линия) и реальный (линия с круглым маркером) сток меди и цинка

В начале второго периода наблюдалось возрастание концентрации в 2-3 раза от значений, наблюдавшихся в конце предыдущего периода. С другой стороны, именно на этот период приходится резкое снижение индекса промышленного производства, которое составило $50 \%$ к значению 1991 года. Уместно было бы предположить, что снижение промышленной активности должно было привести к снижению загрязненности, однако действительное положение дел указывает на противоположную тенденцию. На наш взгляд это было связано с оптимизацией расходов предприятий, которое, выражалось в отключении очистных сооружений, уменьшение расходов на природоохранные мероприятия. Вторая половина периода характеризовалась снижением значений концентрации металлов на фоне восстановления промышленности. К концу периода концентрация металлов в реке достигла значений конца советского периода, на это же время приходится восстановление промышленного производства до уровня 1991 года.

В период дальнейшего подъема промышленности концентрация меди показывала постепенное снижение значений, цинка - колебание в районе 15 мкг/л. Таким образом, восстановление промышленности и ее дальнейший рост не повлекло за собой рост уровня загрязненности медью и цинком.

В последнее время наблюдается отрицательный тренд стока тяжелых металлов (рис. 3). Для этого же периода также характерно постоянное снижение расхода воды у села Верхнелебяжье (расходы взяты за даты отбора проб). Кроме того, также уменьшаются и объемы сброса в Волгу сточных вод.

Для более полной оценки динамики цинка и меди мы рассчитали их баланс. Для этого следует учесть как естественные источники поступления, так и антропогенные. На наш взгляд основными источниками поступления металлов следует считать сток грунтовых вод, поступление с атмосферными осадками и сток сточных вод. На роль естественного источника поступления тяжелых металлов можно назвать сток грунтовых вод, так как поступление с атмосферными осадками сопряжено с разработкой рудников по добыче металлов, поступление в атмосферу с промышленными выбросами. Используя литературные данные [1, 3, 19 , 20], мы получили среднее содержание в грунтовых водах меди и цинка, которое составило 9 и 11 мкг/л. В питании Волги грунтовые воды занимают треть объема, соответственно в реке данный источник будет давать концентрацию растворенных форм на уровне 3 и 4 мкг/л соответственно. Так как растворенные формы меди в воде реки составляют $10 \%$ [5], то в растворенном состоянии медь будет находиться на уровне 0,3 мкг/л. Можно предположить, что 0,3 мкг/л и 4 мкг/л это естественный фон для данных металлов.

Антропогенная составляющая будет слагаться из сточных вод от объектов ЖКХ и промышленности. Как правило $95 \%$ объема сточных вод являются хозбытовыми стоками, $5 \%$ - промышленными. Усредненный состав бытового стока приведенв соответствующих методических рекомендациях [2]. Так, средняя концентрация меди в бытовых стоках находится на уровне 0,02 мг/л, цинка - 0,1 мг/л. Для оценки роли промышленных стоков мы, в качестве ориентира, избрали усредненный состав стока от машиностроительных предприятий. Концентрация меди в промывных водах колеблется от 0,01 до 0,05 г/л, цинка - от 0,01 до 0,06 г/л. Взяв минимальное значение приведенного диапазона и просуммировав его с бытовым стоком, мы получим минимально возможное поступление металлов в Волгу, тоже самое касается максимальных значений. В результате будет получен некий «коридор» ограниченный максимальным и 
Многолетняя динамика и прогноз стока тяжельх металлов на Нижней Волге в связи с реализачией государственной программы «Оздоровление Волги»

Таблицуа

Сток цинка и меди от различных антропогенных источников и предполагаемый уровень концентрации после реализации программы «Оздоровление Волги»

\begin{tabular}{|l|c|c|c|c|c|c|c|}
\hline \multirow{2}{*}{ ТМ } & \multirow{2}{*}{$\begin{array}{c}\text { Стоки от } \\
\text { ЖКХ }\end{array}$} & \multicolumn{2}{|c|}{ Промышленные стоки } & \multicolumn{2}{c|}{$\begin{array}{c}\text { Стоки от ЖКХ } \\
\text { и промышленности }\end{array}$} & \multicolumn{2}{|c|}{ Концентрация } \\
\cline { 3 - 8 } & & $\max$ & $\min$ & $\max$ & $\min$ & $\max$ & $\min$ \\
\hline \multicolumn{8}{|c|}{ Сток и концентрация в 2016 году } \\
\hline цинк & 504 & 15900 & 2650 & 16404 & 3154 & 67,5 & 13,0 \\
\hline медь & 101 & 1325 & 265 & 1426 & 366 & 5,87 & 1,50 \\
\hline \multicolumn{7}{|c|}{ Снижение только стока от ЖКХ } \\
\hline цинк & 55,9 & 15900 & 2650 & 15956 & 2706 & 65,7 & 11,1 \\
\hline медь & 11,2 & 1325 & 265 & 1336 & 276 & 5,50 & 1,14 \\
\hline \multicolumn{8}{|c|}{ Снижение только стока от промышленности } \\
\hline цинк & 504 & 1767 & 294 & 2270 & 798 & 9,34 & 3,28 \\
\hline медь & 101 & 147 & 29,4 & 248 & 130 & 1,02 & 0,54 \\
\hline \multicolumn{7}{|c|}{ Снижение стока ЖКХ и промышленности } \\
\hline цинк & 112 & 3533 & 589 & 3645 & 701 & 15,0 & 2,88 \\
\hline медь & 22,4 & 294 & 58,9 & 317 & 81,3 & 1,30 & 0,33 \\
\hline
\end{tabular}

минимальным значениями. Сопоставив полученные данные с реальным стоком металлов (рис. 3), можно заметить, что медь колеблется в пределах выделенного «коридора», тяготея к его центру, а цинк, также в пределах «коридора», тяготея к его нижней границе.

Такая зависимость позволяет определить предполагаемый уровень концентрации тяжелых металлов в Волге после осуществления всех природоохранных мероприятий, намеченных в рамках государственной программы «Оздоровление Волги». Напомним, что по итогам программы декларировалось снижение объема загрязненных вод, поступающих в Волгу, в 9 раз. Можно выделить три реперных точки уровня концентрации, которые могут быть достигнуты по итогам реализации этой программы. Зависит это от того, на что будут направлены основные усилия по снижению объема загрязненных вод - это уменьшение только объема стоков от объектов ЖКХ, уменьшение объемов стока только от промышленности или уменьшение объемов стока как от ЖКХ, так и от промышленности (для удобства расчетов мы примем это снижение пропорциональным) (таблица).

Так, реализация программы по первому плану приведет к незначительному снижению концентрации металлов. Учитывая то, что концентрация цинка тяготеет к нижней границе диапазона (рис. 3), ее уровень будет близок к значению ПДК для рыбохозяйственных водоемов (10 мкг/л). Так как содержание меди в воде Волги тяготело к середине расчетного диапазона, то при расчете получим следующий уровень концентрации 3,3 мкг/л, что более чем в три раза превышает ПДК для рыбохозяйственных водоемов (1 мкг/л).

Снижение стоков промышленности приведет к резкому снижению уровня концентрации. Уровни концентрации металлов будут находиться ниже значений ПДК. Тоже самое будет наблюдаться при снижении стоков ЖКХ и промышленности. Однако, мы должны учесть тот факт, что помимо поступления от антропогенных источников, металлы поступают с грунтовыми водами или выщелачиваются из подстилающих русло горных пород. Следовательно, концентрация цинка вряд ли упадет ниже 4 мкг/л, а меди ниже 0,33 мкг/л.

Итак, многолетняя динамика металлов, наблюдаемая у села Верхнелебяжье подчиняется динамике расходов Волги. Однако, с начала 2-х тысячных годов концентрация металлов также согласуется с динамикой стока загрязненных вод. Здесь мы можем наблюдать наложение на естественные факторы, антропогенных. Есть вероятность того, что резкое увеличение расходов Волги приведет к резкому росту концентрации металлов, т.е. наблюдаемую тенденцию пока сложно назвать однозначно устойчивой.

Восстановление промышленности, наблюдаемое в начале нашего века, не повлекло за собой резкого возрастания загрязненности речных вод 
металлами. Более того отмечается тенденция к снижению уровня концентрации металлов в воде. Однако, напротив, снижение промышленного потенциала, наблюдаемое в первой половине девяностых, способствовало резкому скачку концентрации меди и цинка.

Полная реализация программы «Оздоровление Волги» по любому сценарию будет способствовать снижению концентрации цинка до уровня ПДК и ниже. Снижение концентрации меди до значений ПДК потребует значительного снижения промышленных стоков.

\section{СПИСОК ЛИТЕРАТУРЫ}

1. Брылев В. А. Родники и реки Волгоградской области / В. А. Брылев, Н. А. Самусь, Е. Н. Славгородская. - Волгоград : Михаил (Арт линия), 2007. - 200 с.

2. Канализация населенных мест и промышленных предприятий / Н. И. Лихачев [и др.]; под общ. ред. В. Н. Самохина. - 2-е изд., перераб. и доп. - Москва : Стройиздат, 1981. - 639 с.

3. Летенкова И. В. Химические показатели качества родниковых вод Солецкого района Новгородской области / И. В. Летенкова, В. Ф. Литвинов // Национальная ассоциация ученых. - 2016. - № 6(22). - С. 107-111.

4. Малютин А. Н. Микроэлементы и органические вещества в системе волжских водохранилищ / А. Н. Малютин, Г. В. Вольпян, В. Ф. Бреховских // Тезисы выступлений к республиканскому семинару. - Москва : НГУ, 1990. - С. 11-24.

5. Моисеенко Т. И. Рассеянные элементы в поверхностных водах суши: Технофильность, биоаккумуляция и экотоксикология / Т. И. Моисеенко, Л. П. Кудрявцева, Н. А. Гашкина. - Москва : Наука, 2006. - 261 с.

6. Народное хозяйство РСФСР в 1985 году : статистический ежегодник / ЦСУ РСФСР. - Москва : Финансы и статистика, 1986. - 398 с.

7. Народное хозяйство РСФСР в 1988 году : статистический ежегодник / Госкомстат РСФСР. - Москва : Финансы и статистика, 1989. - 688 с.

8. Народное хозяйство РСФСР в 1989 году : статистический ежегодник / Госкомстат РСФСР. - Москва : Финансы и статистика, 1990. - 692 с.

9. Народное хозяйство РСФСР в 1990 году : статистический ежегодник / Госкомстат РСФСР. - Москва : Информационно-издательский центр, 1991. - 592 с.

10. Народное хозяйство РСФСР в 1992 году : статистический ежегодник / Госкомстат России. - Москва : Информационно-издательский центр, 1993. - 654 с.

11. Основные черты гидролого-гидрохимического режима нижнего течения р. Волги в 2002 г. / Д. Н. Катунин [и др.] // Рыбохозяйственные исследования на Каспии: Результаты НИР за 2002 г. - Астрахань : Издательство Каспийского научно-исследовательского института рыбного хозяйства, 2003. - С. 37-44.
12. Проблемы качества вод Нижней Волги и Северного Каспия / В. Ф. Бреховских [и др.]. - Москва : Россельхозакадемия, 2013. - 300 с.

13. Российский статистический ежегодник. 1994. Москва : Госкомстат России, 1994. - 799 с.

14. Российский статистический ежегодник. 1996 / Госкомстат России. - Москва : Логос, 1996. - 1202 с.

15. Российский статистический ежегодник / Госкомстат России. - Москва : Логос, 2000. - 642 с.

16. Российский статистический ежегодник. 2005 / Росстат. - Москва, 2005. - 819 с.

17. Российский статистический ежегодник. 2010 / Росстат. - Москва, 2010. - 813 с.

18. Содержание загрязняющих веществ в водоемах Волго-Каспийского бассейна / Д. Н. Катунин [и др.] // Рыбохозяйственные исследования на Каспии: Результаты НИР за 2001 г. - Астрахань : Издательство Каспийского научно-исследовательского института рыбного хозяйства, 2002. - С. 37-41.

19. Химический состав и содержание микроорганизмов в воде из родников г. Кирова / С. Г. Скугорева [и др.] // Биодиагностика состояния природных и природно-техногенных систем : материалы XIV Всероссийской научно-практической конференции с международным участием. - Киров : Радуга-ПРЕСС, 2016. C. $310-315$.

20. Шкаликов В. А. Химический состав основных источников подземных вод территории г. Смоленска / В. А. Шкаликов, И. В. Анкинович // Вестник Воронежского государственного университета. Сер. География. Геоэкология. - 2014. - № 1. - С. 64-67.

21. Эколого-токсикологическая характристика низовий р. Волги и Каспийского моря / С. Н. Егоров [и др.] // Рыбохозяйственные исследования на Каспии : Результаты НИР за 2005 г. - Астрахань : Издательство Каспийского научно-исследовательского института рыбного хозяйства, 2006. - С. 44-65.

\section{REFERENCES}

1. Brylev V. A. Rodniki i reki Volgogradskoy oblasti / V. A. Brylev, N. A. Samus', E. N. Slavgorodskaya. - Volgograd : Mikhail (Art liniya), 2007. - 200 s.

2. Kanalizatsiya naselennykh mest i promyshlennykh predpriyatiy / N. I. Likhachev [i dr.]; pod obshch. red. V. N. Samokhina. - 2-e izd., pererab. i dop. - Moskva : Stroyizdat, 1981. $-639 \mathrm{~s}$.

3. Letenkova I. V. KHimicheskiye pokazateli kachestva rodnikovykh vod Soletskogo rayona Novgorodskoy oblasti / I. V. Letenkova, V. F. Litvinov // Natsional'naya assotsiatsiya uchenykh. - 2016. - № 6(22). - S. 107-111.

4. Malyutin A. N. Mikroelementy i organicheskiye veshchestva v sisteme volzhskikh vodokhranilishch / A. N. Malyutin, G. V. Vol'pyan, V. F. Brekhovskikh // Tezisy vystupleniy k respublikanskomu seminaru. - Moskva : NGU, 1990. - S. 11-24.

5. Moiseyenko T. I. Rasseyannyye elementy v poverkhnostnykh vodakh sushi: Tekhnofil'nost', bioakkumuly- 

программы «Оздоровление Волги»

atsiya i ekotoksikologiya / T. I. Moiseyenko, L. P. Kudryavtseva, N. A. Gashkina. - Moskva : Nauka, 2006. - 261 s.

6. Narodnoye khozyaystvo RSFSR v 1985 godu : ctatisticheskiy ezhegodnik / TSSU RSFSR. - Moskva : Finansy i statistika, 1986. - $398 \mathrm{~s}$.

7. Narodnoye khozyaystvo RSFSR v 1988 godu : ctatisticheskiy ezhegodnik / Goskomstat RSFSR. - Moskva : Finansy i statistika, 1989. - $688 \mathrm{~s}$.

8. Narodnoye khozyaystvo RSFSR v 1989 godu : ctatisticheskiy ezhegodnik / Goskomstat RSFSR. - Moskva : Finansy i statistika, 1990. - $692 \mathrm{~s}$.

9. Narodnoye khozyaystvo RSFSR v 1990 godu : ctatisticheskiy ezhegodnik / Goskomstat RSFSR. - Moskva : Informatsionno-izdatel'skiy tsentr, 1991. - $592 \mathrm{~s}$.

10. Narodnoye khozyaystvo RSFSR v 1992 godu : ctatisticheskiy ezhegodnik / Goskomstat Rossii. - Moskva : Informatsionno-izdatel'skiy tsentr, 1993. - $654 \mathrm{~s}$.

11. Osnovnyye cherty gidrologo-gidrokhimicheskogo rezhima nizhnego techeniya r. Volgi v 2002 g. / D. N. Katunin [i dr.] // Rybokhozyaystvennyye issledovaniya na Kaspii: Rezul'taty NIR za 2002 g. - Astrakhan' : Izdatel'stvo Kaspiyskogo nauchno-issledovatel'skogo instituta rybnogo khozyaystva, 2003. - S. 37-44.

12. Problemy kachestva vod Nizhney Volgi i Severnogo Kaspiya / V. F. Brekhovskikh [i dr.]. - Moskva : Rossel'khozakademiya, 2013. - $300 \mathrm{~s}$.

13. Rossiyskiy statisticheskiy ezhegodnik. 1994. Moskva : Goskomstat Rossii, 1994. - 799 s.

14. Rossiyskiy statisticheskiy ezhegodnik. 1996 / Goskomstat Rossii. - Moskva : Logos, 1996. - 1202 s.

Татарников Виталий Олегович

ведущий научный сотрудник Каспийского морского научно-исследовательского центра, г. Астрахань, E-mail: tatarnikov@ caspianmonitoring.ru

Гаврилова Елена Владимировна

старший научный сотрудник Каспийского морского научно-исследовательского центра, г. Астрахань, E-mail: gavrilova@caspianmonitoring.ru
15. Rossiyskiy statisticheskiy ezhegodnik / Goskomstat Rossii. - Moskva : Logos, 2000. - 642 s.

16. Rossiyskiy statisticheskiy ezhegodnik. 2005 / Rosstat. - Moskva, 2005. - 819 s.

17. Rossiyskiy statisticheskiy ezhegodnik. 2010 / Rosstat. - Moskva, 2010. - 813 s.

18. Soderzhaniye zagryaznyayushchikh veshchestv v vodoyemakh Volgo-Kaspiyskogo basseyna / D. N. Katunin [i dr.] // Rybokhozyaystvennyye issledovaniya na Kaspii: Rezul'taty NIR za 2001 g. - Astrakhan' : Izdatel'stvo Kaspiyskogo nauchno-issledovatel'skogo instituta rybnogo khozyaystva, 2002. - S. 37-41.

19. KHimicheskiy sostav i soderzhaniye mikroorganizmov v vode iz rodnikov g. Kirova / S. G. Skugoreva [i dr.] // Biodiagnostika sostoyaniya prirodnykh i prirodno-tekhnogennykh sistem : materialy KHIV Vserossiyskoy nauchnoprakticheskoy konferentsii c mezhdunarodnym uchastiyem. - Kirov : Raduga-PRESS, 2016. - S. 310-315.

20. SHkalikov V. A. KHimicheskiy sostav osnovnykh istochnikov podzemnykh vod territorii g. Smolenska / V. A. SHkalikov, I. . Ankinovich // Vestnik Voronezhskogo gosudarstvennogo universiteta. Ser. Geografiya. Geoekologiya. - 2014. - № 1. - S. 64-67.

21. Ekologo-toksikologicheskaya kharaktristika nizoviy r. Volgi i Kaspiyskogo morya / S. N. Egorov [i dr.] // Rybokhozyaystvennyye issledovaniya na Kaspii : Rezul'taty NIR za 2005 g. - Astrakhan' : Izdatel'stvo Kaspiyskogo nauchno-issledovatel'skogo instituta rybnogo khozyaystva, 2006. - S. 44-65.

Tatarnikov Vitaliy Olegovitch

Leading Researcher of the Caspian Sea Scientific Research Centre, Astrakhan', E-mail: tatarnikov@ caspianmonitoring.ru

Gavrilova Elena Vladimirovna

Senior Researcher of the Caspian Sea Scientific Research Centre, Astrakhan',E-mail: gavrilova@ caspianmonitoring.ru 